\title{
Alejandra Pizarnik: "No puedo hablar con mi voz sino con mis voces". Los perturbados entre las lilas
}

\section{Paulina Daza}

Universidad de Concepción

E-mail: pdaza@udec.cl

\begin{abstract}
OS perturbados entre las lilas (1969) es la única obra teatral escrita por Ale- jandra Pizarnik. En 1972, en la antología El deseo de la palabra, la autora incluyó un fragmento de este texto con el título Los posédos entre las lilas, pero el texto completo sólo se publicó en el año 2002 en Prosa completa, a cargo de la Editorial Lumen. Esta edición llegó a Chile en el año 2003; en ella se rescata material disperso en revistas literarias y conservado por la Universidad de Princeton (EE.UU.), además de incluir textos inéditos que no contempló la versión real izada hace diez años por la editorial trasandina Corregidor.

En esta obra teatral, en un acto, la autora mezcla todo aquello que ha sido parte de su escritura durante su período de creación que inevitablemente está ligado a su vida, pues es imprescindible recordar que la autora se aferró al intento de hacer de su vida literatura y literatura de su vida, lo que ella misma reconocía diciendo que su vida real no existía pues ésta es sólo literatura.

Así lo afirma, entre otros, Silvia Baron Supervielle, en su prólogo a una amplia antología de Pizarnik publicada en París:

A medida que avanzamos en la lectura de sus textos, no podemos dejar de presentir que, para hacer vivir su obra, ella se ha condenado a una salida única: sacrificar, en cambio, su propia vida (Pizarnik, 1994:14).

Así, su escritura pasa por los mismos períodos quesu vida, o mejor dicho en su escritura se refleja inacabadamente la forma que le dio a su vida. Períodos 0 momentos concebidos por M . Rodríguez como oscilación, fuga y muerte, en su artículo "La galaxia poética latinoamericana. 2ª mitad del siglo XX" (Rodríguez, 2002: 92).
\end{abstract}


L os poséd dos entre las li las pertenece a la última etapa de la escritura de la poeta antes de su suicidio, aquel período en el queha perdido la confianza en su único refugio, el lenguaje, y se encuentra escudriñando más al lá de los límites en busca de un amparo. Patricia Venti, en su artículo "Las diversiones púbicas de Alejandra Pizarnik", explica que

las obras escritas entre 1968 y poco antes de su muerte están impregnadas de ironía, humor y absurdo. Pizarnik quería irritar y llevar al lector "fuera de escena", donde la trasgresión en el lenguaje residiera más en el significante que en el significado (Venti, 2003).

En el mismo artículo se presenta a L os perturbados entre las lilas como una pieza de teatro inserta en la corriente del absurdo, algo así como una parodia de Esperando a G odot, en la que los personajes se burlan del código social y sexual a través de temas como la infancia, la farsa, la muerte y la imposi bilidad de decir lo visible (la ruptura entre lo visible y lo indecible).

Lo que pretendo a través del análisis de esta obra es descubrir cuáles son las líneas de fuga a las que recurre el sujeto textual, cómo deviene hasta fragmentar completamente su yo, desarticulándose (de manera más perceptible que en su poesía) en personajes. Cada personaje correspondería entonces a una línea de fuga en constante movimiento, rozando el límite, acercándose. Cada uno delos personajes presentes en la obra corresponde a un flujo deseante que se desterritorializa, que huye. Una huida buscada constantemente a través de la pluralidad de la poesía. "No puedo hablar con mi voz sino con mis voces", como escribe en "Piedra fundamental" (Pizarnik, 2001:264). Esta vez se apoya en el teatro para desarticular cada voz y dar forma a un personaje con una función, con una máscara que evidencia el "cocktail de yoes" presentes en su escritura, deambulando en su mundo poético-vital.

Cada personaje es entonces una voz que resiste a través del lenguaje y al mismo tiempo que desconfía y se siente traicionada por él. U na verdadera "máquina paranoica", si recurrimos a D eleuze y Guattari en el Antiedipo (1995).

\section{CADA PERSO N AJE UNA FUGA}

¿Y quién te garantiza que vos no sos la sombra de al guno de mis yo?

Cabe recordar para esteanálisis lo postulado por M ario Rodríguez en el artículo antes mencionado: "Pareciera que la idea es: destruye tu yo fijo, molar, para 
conseguir lo único estimable: identidades oscilantes, pasajeras, yoesen fuga" (Rodríguez, 2002: 92); como también lo que se pregunta Cristina Piña en la biografía de Pizarnik: "¿Tendremos que llegar a la conclusión de que, en el caso de Alejandra, lucidez poética y perfección expresiva sólo se logran a costa de un asesinato del yo en 'las ceremonias del vivir'?" (Piña, 1999:116).

Cada personaje es una línea de fuga en devenir constante, en permanente resistencia al poder, a la muerte y al desamparo, al mismo tiempo que cada personaje es una personalidad distinta de Pizarnik.

En general, y con respecto a las personalidades o voces, es posible notar que a través de su poesía "nunca estuvo sola”, es decir, nunca fue una sola Alejandra, un solo "yo" enunciador en sus poemas, siempre había otra u otras que ella reconocía constantemente; en relación a esto podemos encontrar, por ejemplo, en La extracción de pi edra de locura: "Pero el silencio es cierto. Por eso escribo. Estoy sola y escribo. No, no estoy sola. $\mathrm{H}$ ay alguien aquí quetiembla" (Pizarnik, 2001:243).

\section{SEGISM UNDA}

En principio podría decir que este personaje corresponde a aquella voz de la poeta que tiene el poder de la palabra, que a partir del dolor y el sufrimiento se hace fuerte y domina.

D esde las acotaciones explicadas detallada y estrictamente por la autora, es posible descubrir a través del vestuario del personaje la presencia de la carga angustiosa-desesperada-trágica de autores románticos y simbolistas, que aparecen como el recuerdo constante del dolor que guarda Segismunda, quien multiplicada y estoica resiste.

- Capa gris estilo Lord Byron o G eorge Sand

- Pantalones de terciopelo rojo vivo modelo Keats

- Camisa lila estilo Shelley

- Cinturón incandescente modelo M aiakovsky

- Botas de gamuza celeste forradas en piel rosada modelo Rimbaud (Pizarnik, 2003: 166) ${ }^{1}$

Aunquelo anterior podría simplemente representar la estética superficial del personaje, puede pensarse como un flujo literario, una línea de fuga nómada

\footnotetext{
${ }^{1}$ En adelante usaré sólo el año de publicación y el número de la página para las citas de la obra en análisis (Pizarnik, Alejandra. 2003. Prosa completa. Barcelona, Editorial Lumen).
} 
que entra en vecindad con otras (fugas de otros autores) para configurar la presencia del personaje dentro del texto, lo que más adelante vuelve a manifestar con la frase: "Es lo que tengo: la caligrafía de las sombras como herencia" (2003:179).

D esde su primer diálogo, es posible reconocer en Segismunda la descentralización de su yo: “Es verdad que renuncié a ser una persona” (2003:166), lo que inmediatamente evidencia el devenir imperceptible del personaje.

Segismunda es una serie de flujos poéticos provenientes de autores que se mezclan en su vestuario; de otras voces inocentes de trágicas vidas: "Antígona ¿no fui yo? Anna Frank zacaso no fui yo?"; y a partir de su nombre Segismunda, el recuerdo de otro inocente, Segismundo, con el que otros han jugado induciéndolo a confundir la realidad y la ficción // la creación con la vida ("real").

Por este devenir intenta a través de los sueños aproximarse a los deseos de otros, fugarse y entrar en el mundo de otros, ver a través de los sueños un mundo ajeno que la calma.

Seg (con mucho cansancio): No me dejan dormir. Cállense o hablen más bajo. Si pudiera dormir un minuto, un año. Si durmiera, detrás de mis ojos de dormida yo vería los mares y los laberintos y los arcos iris y las melodías y los deseos y el vuelo y la caída y los espacios de los sueños de los demás vivientes. Yo podría ver y oír sus sueños (2003: 173).

A través de sus diálogos Segismunda, poco a poco, deviene en zona de frontera en que de pronto parece ser la misma poesía que se manifiesta para establecer su poder por sobre los otros yo y para defenderse cuando se siente próxima a ser abandonada. Se trataría entonces de un "yo poesía / poema" de Pizarnik que se enfrenta a $\mathrm{C}$ ar, que es un yo cansado, decepcionado y que quisiera abandonarla.

Car: Soñé que vos y yo estábamos "a un paso del adiós"

Seg: ¿Será verdad?

Car: Si lo dice el tango

Seg: ¿Entonces?

Car: M eiré a otro sitio, a cualquier parte. Encontraré otra ciudad, otras calles, otras casa.

Seg: Antes me querías (2003:167).

En el diálogo citado Car comunica el desarraigo que comienza a sentir y

${ }^{2}$ La línea defuga o de ruptura, que conjuga todos los movimientos de desterritorialización, los precipita, los quanta, les arranca partículas aceleradas que entran en vecindad unas con otras, los lleva a formar parte de un plano de consistencia o de una máquina mutante (D eleuze, 1980: 155). 
cómo parece estar perdiendo el lugar en el que se había instalado en Pizarnik³. Esta idea se proyecta en todos los "yoes", en intentos de fuga peligrosos.

Seg: ... yo estaba por encontrar un pequeño lugar solitario, propicio para vivir. Soy una mendiga de tregua. Esta vez la sombra vino a la tarde y no como siempre por la noche. Y yo ya no encuentro un nombre para esto. (Sigue con la mirada el avance de una presencia invisible.) Y ahora, iqué hacemos aquí? Indefinidos, desposeídos, imbéciles. Nos desmoronamos en forma anodina. N uestra condición es tan funesta que ni siquiera puede haber duelo... (2003: 186).

La poesía habla a través de la voz de Segismunda enfatizando como lo haría una "máquina paranoica": D emuestra el peligro que representa vivir con ella y de ella y al mismo tiempo el abismo que significa al ejarse:

Seg: Vivir a mi lado es una suerte de muerte, pero alejarse de mí significa morir... (2003:192).

Car: Estoy cansado de nuestros diálogos.

Seg: Tan nuestros no son (recitando). Soy el silencio, el pensamiento, la lengua y el eco. Soy el mástil, el timón, el timonero, el barco y la roca dondese estrella el barco (2003:193).

A partir de sus constantes flujos no sólo esas aproximaciones caben sobre Segismunda. Su deseo de huida se manifiesta también a través de "huir, pero mientras se huye, buscar un arma" (D eleuze y Parnet, 1980: 154).

Seg: Siento deseos de huir hacia un país más hospitalario y, al mismo tiempo, busco bajo mis ropas un puñal (2003:170).

Es posible reconocer en ella las armas con las que cuenta, las mismas que le otorgan mayor poder que a los otros yo. Es notorio que en el texto no existe un héroe o un personajeque ostente el poder para bien de los otros, ni siquiera para bien desí mismo; Segismunda pliega el afuera sometiendo a los otros personajes a su voluntad. Ella posee el poder dela palabra, del lenguaje, de los sueños y de la creación.

Segismunda tiene el poder de afectar sobre C arol, M acho y Futerina, puede gritarles, hacerlos callar, echarlos, ponerles sólo brazos y no piernas, encerrarlos en el gallinero, por ejemplo:

${ }^{3}$ Recordando que en este período Pizarnik pierde la confianza que tenía en la poesía como herramienta de salvación, arma de sobrevivencia. 
Seg a Car sobre M acho:

Seg: Encerralo en el gallinero (2003:169)

Seg a Car:

Seg: Por supuesto, y ahora ándate (Car permanece inmóvil como si alguien lo estuviera soñando). C ré haber dicho que te fueras (2003: 171).

Pero ella también puede ser afectada 4 por las fuerzas del afuera: el silencio, la oscuridad y evidentementela locura. La locura es una posibleforma de huida, el flujo que la desarticula y la convierte en personaje rizomático en el que "cualquiera de sus puntos puede ser conectado con cualquier otro, y debe serlo" (D eleuze, 1987:13).

Segismunda, como multiplicidad de Alejandra, apela a la no razón: "Pero para qué me sirve tanta razón" (2003:168), pues si la razón no sirvees factible el camino de la locura, de la esquizofrenia tan cercana a Pizarnik ${ }^{5}$. La razón es sedentaria. La locura es nómade. La razón trae el miedo de pasar los límites. La locura es un poder.

\section{CAROL}

A partir de su nombre "Carol" entrega información, tal como sucede con M acho y Segismunda.

En este caso se puede pensar en la ambigüedad de su nombre, un nombre asexuado que podría ser utilizado tanto por un hombre como por una mujer; desde aquí es posible despersonal izar el personaje que se muestra como un "entre", tal como Alejandra.

Creo que el principal rasgo de fuga de $C$ arol proviene de su lenguaje, $C$ arol resiste al poder y deal guna manera a la muerte instalándose en una línea de fuga que posibilita la descodificación del lenguaje. La lengua devieneajena a su curso verbal avecindándose a la música. Así resiste al lenguaje dominante, que es el lenguaje común, sin melodía y rima determinadas:

Car: Estoy harto. (Canturreando). M i noche, tu noche,

mi Ilanto, tu llanto,

mi infierno, tu infierno.

Seg: Lindo tango, miente como los otros (2003:167).

${ }^{4} \mathrm{C}$ ada fuerza tiene a la vez un poder de afectar (a otras) y de ser afectada (por otras), por eso implica relaciones depoder; todo campo defuerzas distribuye las fuerzas en función deesas relaciones y de sus variaciones (D eleuze, 1987:100).

${ }^{5}$ Cabe recordar que Pizarnik pasó susúltimos años internada en un sanatorio, luego de su primer intento de suicidio. 
La línea de fuga de Carol se aproxima a la de otro personaje, otro que necesitaba de frases hechas (consignas), lenguaje ajeno para comunicarse y tener respuestas para su compañero con más conocimientos queél. M e refiero al personaje de Cervantes Sancho Panza, mientras este recurría a refranes populares $\mathrm{C}$ arol recurre a tangos para dialogar con Segismunda. Esto convierte a $\mathrm{C}$ ar en un personaje que resiste, que intenta huir, pero a la vez lo transforma en el "yo" más convencional dePizarnik, el débil, temeroso y preocupado de su tristeexistencia. Esta preocupación por su existencia lo vuelveun personajeconscientede los cambios, de los movimientos, de los flujos. Lo que lo lleva, por ejemplo, a preguntarse "si envejecer fuera útil" (2003:169), sabiendo que si no es así es mejor la muerte, 0 a advertir que en su entorno hay algo que fluye:

Alguien pesca lo que parecía un pescado pero es algo que no termina de pasar. Alguien 0 algo deja oír su impronta respiratoria. Algo fluye y jamás cesa de fluir (2003:171).

D ela misma forma reconocesus deseos de fuga: "Teoó. D ijiste queme fuera. Intento hacerlo desde que me parió mi madre. (Sale)" (2003:171). Seguramente setrata del "yo Pizarnik" queintenta aferrarse la vida evadiendo el refugio que ha buscado: el lenguaje/ poesía, sin estar seguro desu utilidad y sin estar seguro de si al salir de la constante que se le impone realmente estará la vida.

Seg: ... ¿Cómo andas? ¿cómo te sentís?

Car: Voy y vengo

Seg: ¿Por qué te vas?

Car: Si solamente algo anduviera mejor gracias a mi presencia en esta casa. Pero no. ¿Para qué sirvo? (2003:188)

Car: $\mathrm{H}$ e vivido entre sombras. Sal go del brazo de las sombras. M e voy porque las sombras me esperan. Seg, no quiero hablar: quiero vivir (2003:194).

Esta conciencia del fluir, incluso representada con las mismas palabras deC arol, está presente en una de las prosas de Pizarnik. En "C asa de citas" es posible leer:

-Algo fluye, no cesa de fluir

-Dijeque te fueras

-Dijiste que me fuera. Intento hacerlo desde que me parió mi madre (2003:69).

Creo que es probable determinar a C arol como una línea molecular, ya que en él las desterritorializaciones sólo son relativas, puesto quesiempre están compensadas por reterritorial izaciones queles imponen tantos giros y desvíos como equilibrios y estabilizaciones (D eleuze,1987:155) que se manifiestan principal- 
mente por los comentarios, muchas veces irónicos, de Segismunda sobre su persona:

Seg: Un sentimental. Acogedor como un catre. Recurriendo a los tangos por no saber o por no poder decir las propias penas (2003:182).

\section{MACHO Y FUTERINA}

$M$ acho y Futerina se nos presentan como seres inacabados, como seres incompletos sexualmente, al igual que Pizarnik.

A mbos revelan la imposibilidad de acceder a la sexualidad o más específicamente a actos sexuales "normales" o "anormales", en un espacio y un poder determinados que se los prohíbe y que además los limita por su calidad de seres inacabados.

Futerina: iAh, ayer! Ayer era el canto de una guitarra en un al bergue lejano, era el horizonte salvaje en un dormitorio con trapecios y hamacas para ejecutar ciertas posiciones que (en voz más alta) aquí están prohibidas (2003: 172).

Por otro lado, su cualidad de seres inacabados se debe a la decisión de quien en ese momento determinado ejerce el poder sobre ellos.

M acho: ... Recordá cuando los tres camiones embistieron nuestros triciclos. Perdimos brazosy piernas. Segismunda nos compro brazos pero no quiso comprarnos piernas, solamente estos zancos ganchudos para empujar los pedales (Ríen) (2003:172).

D esde la idea de "resistencia" estos personajes resisten al poder a partir de una "sexualidad sin sexo"6 y de cuerpos imperfectos representados a través de la mutilación ${ }^{7}$ (seres sin piernas y con brazos comprados). En relación a estas ideas analizaré ambos personajes por separado, para retomar luego la idea de líneas de fuga.

${ }^{6}$ La lucha por una subjetividad moderna pasa por una resistencia a las dos formas actuales desujeción, una que consisteen individuarnos según las exigencias del poder, otra que consiste en vincular cada individuo a una identidad sabida y conocida, determinada de una vez por todas. La lucha por la subjetividad se presenta, pues, como derecho a la diferencia y derecho a la variación, a la metamorfosis (D eleuze, 1987:139).

${ }^{7}$ Venti dice en su artículo ya mencionado: "Los personajes de la obra teatral están mutilados, los cuerpos son un reflejo de la fragmentación psíquica del yo". 


\section{Macho}

M acho, pensado como un "yo" más del sujeto-Pizarnik, se presenta como una forma de resistencia al poder. Este revela la sexual idad de la autora. C abe recordar que de ella se dice, por ejemplo:

Lo mismo podía flirtear con Silvina O campo que sorprender con un beso apasionado a Ricardo Zelarayán, aunque esto fuera por "prescripción médica" y para "exorcizar deseos lésbicos" (Andonte, 2004: 12).

\section{Para Foucault,}

la relación consigo mismo siempre está abocada a encontrar la sexualidad, según una modalidad que corresponde al modo de subjetivación: la espontaneidad y la receptividad de la fuerza ya no se distribuirán según un papel activo, un papel pasivo, como entre los griegos, sino según al go totalmente distinto, según una estructura bisexual, como entre los cristianos.

Se presenta, entonces este "yo" de la autora como un macho incompleto, del cual se sabe que "Segismunda nos compró brazos pero no piernas, solamente estos zancos ganchudos para empujar los pedales".

La fuerza que, por momentos, ejerceel poder sólo les otorga brazos, es decir, los acepta, los apoya, pero siempre dejando un detalle que los invalida (no tienen piernas y están permanentemente unidos a sus triciclos), al parecer precisamente para poder evitar posibles intercambios sexuales no deseados por quien posee el poder.

El macho incompleto es aquella multiplicidad de Pizarnik sexualmente incompleta como hombre, sexualmente incompleta como mujer ${ }^{8}$. C alidad de incompleto quese refleja a través de intentos frustrados de los personajes ( $M$ achoFuterina) por consumar su deseo. D e esta manera, M acho manifiesta su deseo, pero rápidamente es coartado por sus dificultades corporales.

M acho: Besame, tocame. Tocame un nocturno.

Futerina: No podemos con los triciclos entre las piernas (2003:172).

${ }^{8}$ Roggiano en su artículo sobre Pizarnik "Persona y poesía", al referirse a los atributos femeninos dela deidad D iana (sobreEl Arbol deD iana), determina: "El misterio deAlejandra Pizarnik no podrá explicarse sin comprender este atributo masculino en la persona insoslayablemente femenina del poeta, en la transferencia siempre travestista del soñador, del sonámbulo del visionario o del loco" (Roggiano, 1981: 50-51). 


\section{Futerina}

A partir de las acotaciones presentes antes de que este personaje irrumpa en escena puedo pensar que simbólicamente Pizarnik comunica el desmedro en el que se encuentra Futerina frente a $M$ acho, pues aunque ambos se encuentran en condiciones decadentes, ella lo está más.

(Apareceun triciclo másdesvencijado queel deM acho; lasextremidadesdeFuterina se adhieren a él como garfios..) (2003: 171).

D e esta manera es posible pensar a Futerina como el "yo" mujer-débil ${ }^{9}$ de Alejandra inacabada también. Q uetermina al igual queSegismunda deviniendo imperceptible, desapareciendo de escena simplemente a través de un estruendo tras bambalinas y un simple comentario de Segismunda y Carol.

(Se oyen estertores seguidos por un gemi do largo y luego por un Ilanto animal)

Seg: Andá a ver qué hacen los desechos.

(Car sale, Vuelve con rostro de máscara)

Car: Reventó la ramera (2003:190).

Luego de este análisis por separado puedo pensar que Pizarnik instala a estos personajes en líneas de fuga que intentan evitar el poder, se fugan de él en busca de la sexual idad desterritorial izán dose de lo "socialmente establecido", instalando a través del lenguaje y el gesto aquello que se oculta por "pudor" y se maneja como "tabú", ambos comparten de esta forma con el público-lector su deseo sexual, deseo de vida, sus temores y su acercamiento a la infancia.

En cuanto a aquello que el lenguaje oculta, $M$ acho y Futerina lo manifiestan desterritorializándolo a través de lo obsceno y del doble sentido:

M acho: Escuchá. Te vas a reír hasta mearte (con voz neutra denarrador imparcial) "Acostumbre a su niño desde un principio a adoptar la postura conveniente..."

(Futerina se muere de risa)

M acho: ¡M al pensada! (seríetambién él) “... la postura conveniente aconsejada por la higiene escolar. La necesidad de esa manera de sentarse ha impuesto, puede decirse, el culo normal..."

(Futerina ríe hasta las lágrimas)

${ }^{9} \mathrm{M}$ ujer inacabada es débil-poderosa-débil frente a las identidades molares, poderosa frente a ellas porque las moleculariza. 
M acho (fingiendo asombro): ¿Por azar dije algo gracioso para que te estés riendo como el chorro de bidet? (173-174).

El acercamiento a la infancia es reconocible a través del devenir-niño de ambos personajes, esto se da primero a través de la dependencia de los personajes hacia otro que debe cambiarles pañales:

Futerina: “... ¿Te cambiaron los pañales?" (2003: 173).

M acho deviene niño al recibir un "chupetín", y por unos instantes se alegra y tranquiliza al igual que los niños con un caramelo:

Seg: D ale un chupetín.

(Car saley entra con un chupetín. Poneel chupetín en la mano de M acho, quien lo toma con ansiedad, lo palpa con desconfianza, lo husmea con una sonrisa) (2003: 169).

D esde esta perspectiva puede concebirse a ambos personajes como niños cuya infancia está limitada y controlada por al guien que ejerce el poder, violentándolos a través del lenguaje, asustándolos, maltratándolos.

M acho: Da miedo recordar que se fue niño (2003:174)

D ealguna forma es posiblea través de estos personajes pensar el texto como un cuento infantil en el que deambulan seres débiles dominados por un ser malvado, tal como suele suceder en los cuentos para niños en donde al guna "malvada madrastra" maltrata a los pobres niños débiles o al guna bruja los encierra por pura maldad. La gran diferencia está en que en ese tipo de cuentos el autor siempre acaba con un final feliz, por el contrario en este caso la pobre niña desvalida (Futerina) revienta mientras el niño (M acho) sólo puedellorar dejando su devenir niño y entrando, a través del llanto, en un devenir-animal.

El devenir animal sucede en momentos de desesperación, a través de órdenes de Segismunda 0 a través de gestos de los mismos personajes.

Luego de que M acho tiene el chupetín en sus manos se da cuenta de que no puede comerlo, de que es demasiado duro para él, en ese momento y por una orden de Segismunda M acho pasa violentamente de un devenir-niño (desespe rado que no puede comer lo que desea) a un devenir animal, pues es encerrado en un gallinero, lugar donde lo espera Futerina que también deviene-animal.

M acho (Iloriqueando): ¡Está duro! ¡N o puedo!

Seg: Encerralo en el gallinero.

(C ar lleva a M acho fuera de escena) (2003: 169). 
Luego de la explosión de Futerina, $M$ acho deviene-animal a través de su Ilanto:

(se oyen estertores seguidos por un gemi do largo y luego por un llanto animal )

Seg: ¿Y M acho?

Car: Llora (2003:190).

0 tra forma en que los personajes se fugan de la realidad, es decir la "resisten" la entrega el arma de lo absurdo, al romper el esquema de una conversación "coherente" con pequeñas frases que parecen no tener sentido. D e esta manera evitan los dolores desus incapacidades; por ejemplo, al no poder acercarse, al no poder actuar como seres normales ellos huyen através de un diálogo queirrumpe sin sentido:

M acho: Se me perdió el inodoro

Futerina: ¿Cuándo?

M acho: No se pero ayer estaba (2003: 172).

\section{LYT WIN, LA MUÑECA}

Si me guío estrictamentepor las acotaciones de la autora al comienzo de la obra, al nombrar a los personajes, la muñeca no es uno de ellos, pero a mi parecer, y por razones del análisis, es necesario clasificarla como un personaje importante dentro del texto.

Eso principalmente por una afirmación del propio personaje que melleva a confirmar la idea dela multiplicidad deyoes, dela conciencia de la partición de personalidades involucradas en la obra, lo que me parece más que suficiente para darle a la muñeca la función de un "yo" más de Alejandra.

Lytwin: Soy un yo, y esto que parece poco, es más que suficiente para una muñeca (2003: 187).

Se puede decir que no nacemos con un yo, nos agenciamos uno.

Con respecto a esto Pizarnik no plantea a los personajes como un yo "cerrado" del que se tiene un conocimiento preciso, al contrario deja que cada yo se escape, se fugue a su antojo y devenga o se cruce con otras líneas de fuga. Esto dejando abierta la posibilidad de "escapes" a través de los nombres de los personajes; como mencioné anteriormente cada uno nos sugiere una enunciación colectiva, una serie de voces que convergen en cada personaje. Siguiendo a D eleuze y Guatari "no se puede ser un lobo, siempre se es ocho o diez, seis o siete lobos. 
No queuno sea seiso siete lobosa la vez, sino un lobo entre otros lobos, un lobo con cinco o seis lobos" (D eleuze y G uattari, 1990: 35), analógicamente, no se puede ser un solo yo, siempre se es cinco o seis yo.

D esde una perspectiva biográfica la poeta no era sólo un nombre era también Flora, Buma, Blímele, Alejandra y Sasha, nombres y diminutivos de estos queella llevó durantesu vida. Esto además de la inexactitud de su apellido, que comenta Cristina Piña en su biografía, Pizarnik o Pozharnik, lo que le da seguramentela certeza de que un nombre no es sólo un yo o que un yo no es sólo un nombre sino que posiblemente muchos.

Según D eleuze,

el nombre propio no designa un individuo: al contrario un individuo sólo adquiere su verdadero nombre propio cuando se abre alas multiplicidades que lo atraviesan totalmente, tras el más severo ejercicio de despersonalización. EI nombre propio es la aprehensión instantánea de una multiplicidad (D eleuzey Guattari, 1990: 43).

Volviendo a los personajes, especialmentea la muñeca, ella parecetener conciencia de ser un yo, un "yo" que se presenta casi inesperado, un yo que atemorizaba a Pizarnik. Con esto me refiero a un asunto que menciona Piña en la biografía de la poeta: "Ella se identificaba con una frase de Jean Paul Sartre que incluso copió al guna vez para una amiga: 'tenía cuatro años, estaba sentado en la puerta de mi casa, y de repente pensé soy un yo y tuve miedo'" (Piña, 1999: 27). Este asunto transforma a la muñeca en un "ser infeliz", pues tener conciencia de un único yo no significa tener tranquilidad, por el contrario significa temor. Por otro lado, nos recuerda que si la muñeca es el doble de Segismunda, hablamos del doble que tiene conciencia de su fin sin salida, sin fugas, centrándose, unificándose, que es precisamente a lo que Pizarnik temía.

Al pensar a la muñeca como el doble de Segismunda debemos recordar que Segismunda, de entretodos los "yoes" pareceser el doblemás cercano a Pizarnik, en una serie de dobles, 0 en una serie de imágenes que se reflejan en espejos.

Para M arta Gallo, en su artículo "Los espejos de Alejandra Pizarnik", en muchos de los poemas de Pizarnik existe una "infinita repetición de imágenes del yo hasta perderlo y confundirlo con simulacros imaginados, pero no por eso menos reales" (G allo, 1983: 10). Además supone "imágenes del yo quelo antagonizan, lo repiten y lo dispersan de forma que termina por anular un único yo".

En mi opinión esto es lo que ocurre con los personajes de L os perturbados entre las lilas en relación con Alejandra. Al igual que en un espejo, el reflejo es siempre lo contrario, "el revés", por lo tanto aquello que se refleje será siempre una representación imperfecta: 


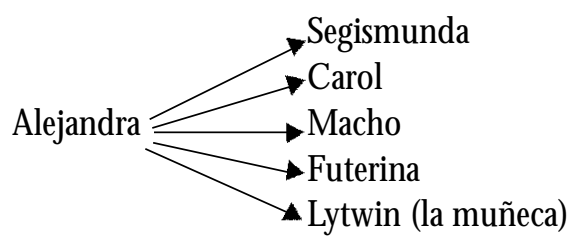

Y de esta misma forma:

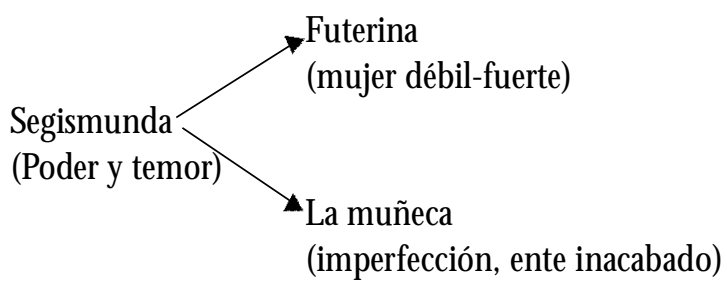

Acerca del doble podría decir quela muñeca corresponde a unainteriorización del afuera, pues, siguiendo las ideas de Foucault, "el doble nunca es la proyección del interior, al contrario, es una interiorización del afuera. N o es un desdoblamiento de lo Uno, es un redoblamiento de lo 0 tro. No es una reproducción delo mismo es una repetición de lo diferente" (D eleuze, 1987:129), por lo cual es posible afirmar que Lytwin es la imagen imperfecta de Segismunda a la vez que Segismunda es un redoblamiento de Alejandra.

Car: Aquí tenés a tu doble.

Seg: iG olpeaste a mi doble!

Car: 0 jalá pudiera matar a tu doble.

Seg: M i todo inofensiva muñequita (la acaricia); pensar que ella ni piensa que duerme (2003:194).

Al igual que M acho y Futerina, la muñeca puede ser pensada como otro yo en el que se ve reflejada la sexualidad inacabada de Pizarnik.

Seg: 0 lvidaste ponerle sexo ${ }^{10}(2003: 181)$.

Por último, en relación a la M uñeca, este "personaje" deambula a través de muchas de las prosas de la autora y se presenta además como un símbolo que la acompaña en su vida cotidiana. Con respecto a ello, Piña advierte:

${ }^{10} \mathrm{C}$ omo los surrealistas, sus maestros de la primera hora, Alejandra proponía una integración de los opuestos y, aún más, una anulación de los contrarios (Piña, 1999). 
Siempre tuvo muñecas en su cuarto o en su departamento, como un símbolo siniestro de la infancia devastada por la muerte. Porque sus muñecas son como restos o harapos del mundo inocente de la niñez, autómatas carentes de toda ingenuidad... (1999: 149).

Por lo cual la presencia de Lytwin viene a reafirmar la idea de la infancia como una etapa dela vida a la cual se le temey no se quiere regresar, un mundo en que a través de una muñeca (las muñecas) se nos señala que todo es falso.

\section{EL PLIEGUE COMO LUGAR EN QUE SE IN STALAN LOS PERSO N AJES}

Car: Alguna vez, tal vez, encontraremos refugio allí donde comienza la realidad verdadera.

Los personajes invaden el espacio de Pizarnik como a G irondo, por ejemplo, lo rodean "personalidades". Estas personalidades, como ya se ha visto, dialogan entre sí, ejercen poder unas sobre otras, resisten al poder y la muerte, intentan huir del poder y la muerte para lo que, como ya he comentado, utilizan distintos medios, pero también es importante el lugar que habitan, el lugar en que Pizarnik los ha alojado y del cual sería interesante investigar si se trata de un refugio o un lugar del cual también desean huir, de un mundo lejano, pero no exterior sino que interior al sujeto.

El espacio escénico que plantea Pizarnik, el espacio en que deambulan los personajes es el simulacro del lugar en que seguramente se encuentran las voces dePizarnik que han transitado en su poesía, una plaza de gran belleza metafísica. Puedo pensar que este lugar es precisamente el lenguaje 0 , pensado de manera más drástica, lo que queda del lenguaje después de la traición y el desamparo. A este lugar accede Pizarnik en su poesía a través de desterritorializaciones y territorializaciones.

En esta obra teatral instala a suspersonajes, sus voces, fuera del límite, tal vez en la muerte. Lugar que es el amparo y la desprotección ( máquina paranoica) al mismo tiempo, como lo es el lenguaje.

Este espacio se podría identificar entonces como un pliegue, si el lugar es el lenguaje, éste seha plegado para ser "habitado" por los "yoes" de Alejandra. Este es el lugar que permite a Alejandra multiplicarse, sabiendo que no se trata de una multiplicación de dobles, sino de una serie de flujos en constante devenir. En el pliegue las multiplicidades de Alejandra adquieren nombre y características marcadas, convirtiéndose en distintas líneas de fuga ${ }^{11}$.

11 "El punto más intenso de las vidas, aquel en el que se concentra su energía, se sitúa allí 
Creo que es posible incluso establecer el pliegue de subjetivación ${ }^{12}$ en el que se encuentran los personajes, se trata del cuarto pliegue, el del afuera, el último; el que constituye lo que Blanchot llamaba una "interioridad de espera". En él el sujeto espera de modos muy diversos, la inmortalidad, o bien la eternidad, la salud, la libertad, la muerte, la renuncia... (D eleuze, 1987:137).

Al relacionar la fecha de escritura de esta obra y su cercanía con el suicidio de Pizarnik puedo pensar que el único espacio o lugar que deseaba Pizarnik en medio de su desamparo era precisamente la muerte, lo que podría significar que tal vez no existe reterritorialización luego de esta obra.

El tema dela muerte y de la espera de la muerte como si estuviera próxima a venir puede verse en el diálogo de Segismunda en quemenciona al "lobo gris"13:

Seg: C ar, te hablo de la soledad mortal. $\mathrm{H}$ ay cólera en el destino puesto que se acerca, entre las arenas y las piedras, el lobo gris... ¿Y entonces, Car? Porque romperá todas las puertas, porque sacará afuera los muertos para que devoren a los vivos, para que sólo haya muertos y los vivos desaparezcan. No tengas miedo del lobo gris. Yo lo mencioné para comprobar que existe y porque hay una voluptuosidad enorme en el hecho de comprobar. Sólo las pal abras hubieran podido salvarme, pero estoy demasiado viviente. $\mathrm{No}$, no quiero cantar muerte. M i muerte...el lobo gris...la matadora que viene de la lejanía... ¿№ hay alma viva en esta ciudad?... (2003:180).

A demás, a través de la biografía de Pizarnik desarrollada por Piña, es posible saber que Pizarnik no sólo deseaba la muerte en sus últimos días, sino quesiempre la esperó, siempre sintió curiosidad por ella, incluso la deseó para al fin descubrirla. Según Piña, desde su adolescencia Pizarnik advertía a sus amigas: "¿Sabés?, yo quisiera morirme para saber que hay detrás" (Piña, 1999: 70).

Volviendo a la idea de pliegue. En este pliegue Segismunda puede ser libre, pues puede romper con los códigos establecidos ${ }^{14}$ para actuar como un flujo deseante que se relaciona con los otros yoes y ejercer poder sobre ellos.

dondeéstos se enfrentan al poder, forcejean con él, intentan utilizar sus fuerzas o escapar a sus trampas" (D eleuze, 1987:125)

${ }_{12}$ Para Foucault existen cuatro plegamientos, cuatro pliegues de subjetivación (D eleuze 1987:137).

${ }_{13}^{13}$ Piña menciona, en la biografía de Pizarnik, queluego dela muertedesu padre, la muerte se había convertido en la Loba azul, la sombra y la presencia de ésta ocupaba gran parte de sus últimos poemas.

${ }^{14}$ Es necesario que de los códigos morales que efectúan el diagrama aquí y allá (en la ciudad, la familia, los tribunales, los juegos, etc.) se libere un "sujeto" que rompe, que ya no depende del código en su parte interior (D eleuze, 1987:133). 
Existe cierto momento dela obra, más o menos en la mitad de ella, en quela plaza de gran belleza metafísica se ve destruida, esto sucede tras la representación de la "opera en 18 actos" de Segismunda: Al encender las luces, Seg y Car aparecen en el mismo lugar y en la misma postura, pero como si en el lapso de la representación de la ópera hubiese estallado una bomba. La - "plaza metafís ca"- ha quedado en ruinas. Es decir, lo queal comenzar era un lugar acogedor se destruye, se convierte en un lugar inhabitable, en un lugar que ha perdido el encanto, en donde posiblemente ya no se desea permanecer.

Esta manifestación de teatro en el teatro ${ }^{15}$, probablemente imposible de representar por la rapidez de los sucesos, a no ser tal vez a través de métodos tecnológicos, sugi ere la idea de dos períodos, un antes del derrumbe de la plaza metafísica y un después del derrumbe, lo que tiene relación con la idea de un antes del lenguaje (pliegue de sobrevivencia y espera) como refugio y un después de la traición del lenguaje que la deja sin refugio.

El lugar en el que se encuentran los personajes es aquel desde donde emerge la poesía, donde la poesía lucha por subsistir. Podría ser, tal vez, aquel lugar que Pizarnik menciona en el poema "El sueño de la muerte o el lugar de los cuerpos poéticos" en La extracción dela piedra delocura:

$\mathrm{H}$ ablo del lugar en que sehacen los cuerpos poéticos - como una cesta llena de cadáveres de niñas. Y es en ese lugar donde la muerte está sentada, viste un traje muy antiguo y pulsa un arpa en la orilla del río lúgubre, la muerte en un vestido rojo, la bella, la funesta, la espectral, la que toda la noche pul só un arpa hasta que me adormecí dentro del sueño (2003: 255).

Es posible a través de la poesía de Pizarnik descubrir que en ella siempre ha estado presente la conciencia de un afuera y un adentro. En el período que posiblemente se podía clasificar como el paso de lenguaje como refugio al lenguaje como desprotección, Pizarnik escribe: "M urieron las formas despavoridas y no hubo más un afuera y un adentro. N adie estaba escuchando al lugar, porque el lugar no existía" (Pizarnik, 2001: 217) ${ }^{16}$. Este mismo lugar que parecía

${ }^{15} \mathrm{H}$ ellamado teatro y no ópera a esta brevey violenta intervención delos supuestos treinta y cinco ancianos en escena, no por una confusión entre los términos ópera y teatro, si no porque creo que resultaría difícil, en tan breve momento, para el público establecer una ópera y no un instante de "teatro en el teatro".

Teatro en el teatro, a partir del Diccionario de términos teatrales de Pavis, corresponde al "tipo de obra cuyo contenido temático es, en parte, la representación de una pieza teatral. La obra externa produce la ilusión de que asistimos simultáneamente, como público, a su representación y a la de la obra interna". (Pavis, 1990: 490).

${ }^{16}$ Este fragmento perteneceal poema "C ontemplación" del libro La extracción de la piedra delocura. 
existir y de pronto ya no existe podría verse reflejado en la obra dramática en el momento que la bella plaza metafísica ha quedado en ruinas luego de la representación de la ópera escrita por Segismunda.

Segismunda: A hora ni siquiera queda lo que yo había soñado. Tanto mejor, ya nada podrá desilusionarme (2003:179).

En el mismo libro citado anteriormente escribe: "No quiero saber. No quiero más que un silencio para mí y las que fui un silencio como la pequeña choza que encuentran en el bosque los niños perdidos" (Pizarnik, 2001: 248).

\section{BIBLIO GRAFIA}

Andonte D racos, Carolina. 2004. "El enigma de Alejandra Pizarnik se revela", en El M ercurio, domingo 8.

Bordelois, Ivonne. 1998. Correspondencia Pizarnik. BuenosAires: Editorial Seix Barral.

D eleuze, Gilles. 1987. Foucault. Buenos Aires: Editorial Paidós.

D eleuze, G illes y G uattari, Félix. 1990. M il mesetas. Valencia: Editorial Pre-Textos.

D eleuze, Gilles y Guattari, Félix. 1995. El Anti Edipo, capitalismo y esquizofrenia. Barcelona: Editorial Paidós.

D eleuze, G illes y Parnet, Claire. 1980. D iálogos. Valencia: Editorial PreTextos.

Evangelista, Lidia. 1996. "La poética de Alejandra Pizarnik", en Atenea N 473: 4151

Gallo, M arta. 1983. "Los espejos deAlejandra Pizarnik", en Letras de BuenosAires N 9: $9-20$.

Pavis, Patrice. 1990. Diccionario de términos teatrales. Buenos Aires: Editorial Paidós.

Paz, $O$ ctavio. 1998. El arco y la lira. M éxico: Fondo de Cultura Económica.

Piña, Cristina. 1999. Alejandra Pizarnik. Una biografía. Buenos Aires: Ediciones C orregidor.

Pizarnik, Alejandra. 1994. Poesía completa y prosa selecta (edición preparada por C ristina Piña). Buenos Aires: Ediciones Corregidor.

Editorial Lumen.

2001. Poesía completa (edición a cargo de Ana Becciú). Barcelona:

2003. Prosa completa. Barcelona: Editorial Lumen.

Rodríguez, M ario. 2002. "La galaxia poética latinoamericana. $2^{\mathrm{a}}$ mitad del siglo XX", en Acta Literaria $\mathrm{N}^{\circ}$ 27: 92-98.

Roggiano, Alfredo. 1981. "Alejandra Pizarnik: Persona y poesía”, en Letras de Buenos Aires $N^{\circ}$ 2: 49-58.

Venti, Patricia. 2003. "Las diversiones púbicas de Alejandra Pizarnik", en Espéculo. Revista de Estudios Literarios. Universidad Complutense de Madrid. EI URL de este documento es: http://www.ucm.es/info/especulo23/numero/pizarnik.html 